\title{
LIBERDADE DE EXPRESSÃO E O PROBLEMA DA REGULAÇÃO DO DISCURSO DO ÓDIO NAS MÍDIAS SOCIAIS ${ }^{1}$
}

\author{
FREEDOM OF EXPRESSION AND THE PROBLEM OF \\ REGULATING HATE SPEECH IN SOCIAL NETWORKS
}

INGO WOLFGANG SARLET ${ }^{2}$

RESUMO: O assim chamado discurso do ódio, mesmo não sendo, como tal, um fenômeno novo, ganhou a dimensão de um problema mundial, com um impacto crescente e mais devastador, gerando a necessidade urgente de adequada regulação em termos de prevenção e proibição, o que deve se dar em nível nacional e internacional. Um dos maiores desafios é o de achar um equilíbrio adequado entre a Liberdade fundamental de expressão e a proteção da dignidade da pessoa humana e os direitos de personalidade, contra todo e qualquer manifestação que possa ser enquadrada no conceito de discurso do ódio. Nesse sentido, o objetivo do presente texto é o de discutir o problema à luz da jurisprudência da Corte Europeia de Direitos Humanos (o caso Belkacem vs. Bélgica), o recente German Act to Improve Enforcement of the Law in Social Networks (Netzwerkdurchsetzungsgesetz - German Network Enforcement Act) e a ordem constitutional brasileira.

Palavras-Chave: Liberdade de Expressão; Discurso do Ódio; Mídias Sociais; Regulação.

\footnotetext{
${ }^{1} \mathrm{O}$ autor agradece ao DAAD - Serviço de Intercâmbio Acadêmico Alemão, pelo auxílio financeiro que propiciou a participação, como palestrante no Congresso Bienal dos Centros de Estudos Europeus e Alemães, realizado em Berlin, dezembro de 2018, onde discorreu sobre o tema. Agradecimentos também são devidos à minha esposa Gabrielle Bezerra Sales Sarlet, pelo auxílio na pesquisa de algumas das fontes bibliográficas que muito enriqueceram o texto.

2 Professor Titular da Escola de Direito e do Programa de Pós-Graduação em Direito da PUCRS. Desembargador aposentado do TJRS e Advogado. Contato: ingo.sarlet@pucrs.br. Lattes: http://lattes.cnpq.br/7185324846597616.
} 
ABSTRACT: Hate speech, although not being, as such, a recent phonemena, became a worldwide challenge, whit increasing and more devastating impact, attracting the urgent need of adequate regulation in terms of prevention and interdition, something to be at national and transnational level. One of the major challenges is to find the proper balancing between the fundamental freedom of expression and the protection of human dignity and personality rights against any kind of manifestation that is qualified as hate speech. In this sense, the aim of this paper is to discuss the problem in light of the European Court of Human Rights case law (the Belkacem vs. Belgium decision), the recently enacted German Act to Improve Enforcement of the Law in Social Networks (Netzwerkdurchsetzungsgesetz - German Network Enforcement Act) and the Brazilian constitutional order.

KEYWORDS: Freedom of Expression; Hate Speech; Social Media; Regulation.

\section{INTRODUÇÃO}

Que o ódio e sua veiculação pelas mais diversas formas não é um fenômeno novo, já existindo onde se faz presente mais de uma pessoa, mas segue, cada vez mais e especialmente em virtude do potencial de difusão da internet, atingindo dimensões de alto impacto, não parece ser objeto de maior discordância. Pelo contrário, cuida-se de algo presente no nosso dia-a-dia e que tem tido consequências devastadoras sobre a vida de inúmeros indivíduos, famílias e coletividades, sem falar no impacto sobre a sociedade, economia, política e cultura. Para ilustrar tal fenômeno, basta apontar o recrudescimento das manifestações e ações de caráter xenófobo e racista, assim como a violência moral e mesmo física direcionada a minorias religiosas, ou então guiada por preconceitos ligados ao gênero, orientação sexual, entre outros.

De modo a promover aqui e desde logo um acordo semântico, sabendo-se da polêmica que envolve a adoção de um conceito aberto e abrangente, o discurso de ódio envolve todos os casos que expressam manifestações voltadas para a cultura da humilhação, englobando ações como cyberbulling, revenge porn e o assim chamado linchamento virtual ${ }^{3}$. Note-se que, de acordo com recomendação do Conselho da Europa - de crucial relevância também para o presente texto - cada expressão que divulga, incita, promove ou justifica ódio racial, xenofobia, antisemitismo ou qualquer outra forma de intolerância, incluindo intolerância causada por um nacionalismo de cunho agressivo, etnocentrismo ou hostilidade em relação

3 Takimoto (2017). 
a minorias, imigrantes e pessoas de origem estrangeira é considerado uma espécie de discurso do ódio ${ }^{4}$.

No caso do ambiente digital, em especial a partir da versão 2.0 da Internet e de sua abertura, destacando-se, no contexto, as assim chamadas mídias sociais e os provedores de pesquisa e compartilhamento, as dimensões temporal e espacial restaram substancial e irreversivelmente (salvo alguma mudança que por ora não se pode divisar), visto ser o ambiente da Internet cada vez mais um fenômeno global e onipresente.

Ainda em caráter preliminar a aproximando-nos mais do nosso objeto, é sabido que manifestações de ódio na internet, geralmente causam efeitos nefastos posto que afetam não apenas os indivíduos, em especial pertencentes a grupos vulneráveis, quanto reforçando estruturas sociais que supostamente legitimam condutas discriminatórias, sejam individuais sejam institucionais. ${ }^{5}$ Assim, se numa perspectiva individual são comuns efeitos como depressão, baixa autoestima, tentativas de suicídio, auto exclusão e automutilação pelas pessoas vitimadas, numa perspectiva coletiva, quando o ódio é destilado contra determinados grupos sociais, o impacto perverso envolve uma espécie de efeito difuso, porquanto toda e qualquer ofensa é, em geral, destinada a provocar o desgaste dos laços de pertencimento social. ${ }^{6}$

Nesse contexto, o discurso do ódio (assim como o fenômeno - em parte correlato - das fake news, da desinformação) acirra sectarismos, instila a divisão social, gera níveis preocupantes de instabilidade política e mesmo representa, cada vez mais, ameaças concretas para a democracia. Para tanto, basta lançar um olhar sobre o avanço dos extremismos e radicalizações sociais e políticas em todo Mundo, inclusive - e, para o nosso efeito - em especial na Alemanha, Europa e no Brasil, onde se verificam níveis maiores de populismo, ademais de uma ampliação dos movimentos de natureza neofascista, dentre outros.

Na perspectiva do Direito, um dos principais desafios segue sendo o de buscar assegurar um equilíbrio entre o exercício pleno da liberdade de expressão nas suas mais diversas dimensões, por um lado, e a necessária proteção da dignidade da pessoa humana e dos direitos de personalidade, por outro, mas também o de operar como instrumento para a afirmação, do pondo de vista transindividual, de um ambiente com níveis satisfatórios de tolerância e reconhecimento. Sem isso, o próprio Estado Democrático de Direito, necessariamente livre, plural e igualitário,

\footnotetext{
${ }^{4}$ Cf. EUROPEAN UNION. Council of Europe. European Council Recommendation n. 97/20 of the Committee of Ministers to member states on "hate speech", 1997, é de ser considerada uma forma de discurso do ódio "Every expression that spread, incitate, promote or justify racial hate, xenofobia, anti-semitism or any other form of intolerance, including intolerance caused by agressive nationalism and ethnocentrism, discrimination or hostility against minorities, migrants and peoplem from foreign origin".

5 Thweatt (2001).

${ }^{6}$ Waldron (2012, p. 05).
} 
estará em risco. Não é à toa, que Frank Michelman, sublinha que a relação entre democracia e liberdade de expressão é de um recíproco condicionamento e assume um caráter complementar, dialético e dinâmico, de modo que, embora mais democracia possa muitas vezes significar mais liberdade de expressão e vice-versa (mais liberdade de expressão indica mais democracia), também é correto que a liberdade de expressão pode acarretar riscos para a democracia e que, por sua vez, pode comprometer a liberdade de expressão. ${ }^{7}$

É claro que, conforme já referido, a possibilidade de o Estado ou a comunidade poderem regular o conteúdo da liberdade de expressão e as suas formas de veiculação, é assunto de alta sensibilidade e complexidade, além de não ser novo. Pelo menos desde a Declaração de Direitos Inglesa de 1689 (embora não com o status de um direito fundamental constitucional) a liberdade de expressão (incluindo a de informação) ostenta lugar cimeiro nos catálogos das constituições dos Estados Democráticos e assume a condição de direito humano nos tratados internacionais de nível universal (ONU) e regional, como é o caso, para o nosso propósito, da Convenção Europeia de Direitos Humanos, Carta Europeia de Direitos Fundamentais e da Declaração Interamericana de Direitos Humanos.

Nesse contexto, seja em sede internacional (supranacional), seja no plano doméstico, diversas medidas já tem sido tomadas pelas instâncias legislativas, executivas e judiciárias, medidas que, todavia, nem sempre são adequadas do ponto de vista da sua eficácia, mas também são controversas no que diz com a sua legitimidade jurídica, em especial quando avaliadas na perspectiva dos catálogos de direitos humanos e fundamentais.

Os problemas que se tem apresentado e reclamam equacionamento, bem como os respectivos desafios, são muitos e aqui apenas podem ser analisados à luz de alguns exemplos. Assim, o que se busca é identificar, discutir e avaliar, se e em que medida a regulação em sede legislativa e administrativa, assim como - e aqui com particular destaque - a intervenção dos tribunais, tem sido capaz de ao mesmo tempo assegurar, com vigor e eficácia, a liberdade de expressão, mas combater os eventuais abusos naquilo em que se envereda pelo assim chamado discurso do ódio no ambiente digital.

Mesmo que não se possa mais diferenciar claramente as dimensões off-line e on-line, grande e cada vez maior volume do que se encontra em bancos de dados e publicações originalmente não digitais, acaba sendo digitalizado e circula pela Internet, com todo o impacto que é peculiar a tal ambiente.

Contudo, além do problema jurídico-político de se, como e o quanto se pode ou mesmo deve intervir na liberdade de expressão, coloca-se o desafio relativamente à eficácia e efetividade da regulação, tendo em conta, dentre outros aspectos, o fato de que soluções locais ou mesmo regionais por si só já se apresentam como difíceis e que um enforcement minimante eficaz no plano global

${ }^{7}$ Cf. Michelman (2007, p. 49 e ss). 
por ora se revela praticamente inviável, independentemente da interrogação se se trata de algo desejável.

Certo é que não apenas o poder público (nacional e supranacional), mas também os próprios atores privados (incluindo os gigantes da internet como Facebook, Google, etc.) estão cientes dos perigos e riscos gerados pelo discurso do ódio, como já têm implementado um sem números de interessantes e criativas - muito embora não necessariamente incontroversas - iniciativas. Além disso, Juízes e Tribunais encontram-se quase que soterrados de causas relacionadas ao tema, nas mais variadas esferas do Direito, instados a intervir nas opções (ou omissões) legislativas e administrativas, bem como decidir sobre os conflitos entre os particulares e o Estado e os atores privados entre si, produzindo um manancial jurisprudencial como nunca dantes visto sobre o tema.

$\mathrm{Na}$ perspectiva legislativa, um exemplo a ser destacado (e não como necessariamente positivo ou negativo, à primeira vista) é o da recente legislação alemã para a regulação de conteúdo abusivo na Internet no que diz com as grandes mídias sociais, o assim chamado Netzwerkdurchsetzungsgesetz (Act to Improve Enforcement of the Law in Social Networks, doravante referido como German Network Enforcement Act - GNEA), de 01.09.2017. ${ }^{8}$

Diferentemente do que se verificou na Alemanha, no caso brasileiro, em que pese os novos parâmetros do Marco Civil da Internet e da Lei Geral de Proteção de Dados, que entrará em vigor apenas em 2020, inexiste um diploma legislativo específico destinado a regular o conteúdo das publicações on-line nas mídias sociais, mas sim, um conjunto de disposições normativas aplicáveis ao ponto, que, contudo, carecem de equacionamento, harmonização e até mesmo correções e ajustes.

No plano da Europa (em perspectiva transnacional), em especial no concernente ao espaço territorial de vigência da Carta Europeia de Direitos Fundamentais (apenas União Europeia) e da Convenção Europeia de Direitos Humanos, igualmente ainda não existe um marco normativo formal de caráter vinculativo específico, mas prescrições relacionadas à proteção de dados, que podem, a depender do caso, ser aplicadas ao problema do discurso do ódio, bem como algumas manifestações normativas em sede do que se designa de um soft law, sobre o que voltaremos a nos manifestar.

Mas com ou sem regulação legislativa e administrativa específica, não faltam decisões judiciais sobre o tema, decisões que, de resto, em se tratando dos tribunais superiores nacionais e das instâncias judiciárias internacionais, tem estabelecido alguns parâmetros, com os quais se pode ou não concordar, mas que necessitam ser cada vez mais expostos e discutidos.

Assim, o que se pretende é propiciar não apenas uma visão panorâmica sobre o estado da arte na Alemanha e na Europa (na perspectiva nacional, transnacional e

8 Deutschland (2017). 
supranacional), mas também fornecer eventual subsídio para o avanço das discussões sobre o tema/problema no Brasil. Nesse sentido, a hipótese que aqui se enuncia, é a de que, a despeito dos avanços significativos no plano regulatório, ademais de uma série de importantes decisões dos Tribunais, existem lacunas importantes a serem colmatadas, que, embora a dificuldade de assegurar uma solução para todos os desafios, poderiam, pelo menos em alguma medida, aperfeiçoar o desempenho do nosso marco regulatório em matéria legislativa e administrativa, mas também por parte do Poder Judiciário, concernente ao enfrentamento eficaz do problema do discurso do ódio.

A escolha da Alemanha e da Europa - como ambientes jurídicos a serem analisados e avaliados para efeitos de seu possível aproveitamento para o caso brasileiro - se justifica tanto pelo fato de que no caso alemão foi editada possivelmente a primeira (pelo menos a que por ora se tornou mais conhecida ${ }^{9}$ ) legislação específica para regular conteúdos nas mídias sociais, ao passo que na segunda, em que pese a falta de uma regulação da mesma natureza (vinculativa e passível de invocação eficaz na esfera judiciária), diversas decisões - aqui selecionada uma das mais recentes e relevante para a presente análise - do Tribunal Europeu de Direitos Humanos (TEDH).

Note-se que também ao nível do direito europeu, à míngua de diploma normativo específico, as Cortes referidas tem lançado mão, como parâmetro de controle, dos direitos humanos e fundamentais contemplados na Convenção Europeia dos Direitos Humanos (CEDH) e da Carta de Direitos Fundamentais da União Europeia (CDFUE) e de outros diplomas normativos, como é o caso do Regulamento Geral Europeu de Proteção de Dados (RHEPD).

Antes, contudo, de investir na apresentação e exame do GNEA e da jurisprudência dos Tribunais Europeus, é o caso de iniciar com algumas notícias de caráter mais geral sobre a delicada e complexa relação entre a liberdade de expressão e de informação e outros direitos fundamentais, destacando-se os direitos de personalidade, na Alemanha, na Europa e no Brasil. Sem isso, não será possível, pelo menos não com a necessária correção, discutir os problemas específicos que envolvem o discurso do ódio e a sua regulação na internet.

\footnotetext{
9 Note-se que, entrementes, em 09.07.2019, foi aprovada, na França, lei que, inspirada diretamente no German Network Enforcement Act, obriga as redes sociais a retirarem conteúdos que exprimam discurso do ódio da internet. Todavia, não será aqui que teremos condições de comentar o novo diploma legal, em virtude do prazo para o fechamento do presente texto.
} 


\section{NOTAS SOBRE O SEMPRE ATUAL PROBLEMA DAS TENSÕES/CONFLITOS ENTRE A LIBERDADE DE EXPRESSÃO E OS DEMAIS DIREITOS FUNDAMENTAIS: ALEMANHA, EUROPA E BRASIL}

Elementos essenciais de uma ordem democrática e corolários da tradição liberal-individualista que radica na base do moderno constitucionalismo, as liberdades de expressão e de reunião, nunca deixaram de ser ameaçadas e violadas, carecendo de particular proteção, exigência que se agudiza em termos quantitativos e qualitativos no âmbito digital.

De importância cimeira, nesse contexto, é o papel assumido pela liberdade de expressão nas mais diversas ordens jurídicas, com destaque, contudo, para o problema de qual a posição da liberdade de expressão, em termos de proteção estatal, em relação aos demais direitos fundamentais. As respostas, como se sabe, são diversas e, embora existam elementos importantes em comum, ademais de uma crescente aproximação de modelos, por conta não apenas dos processos de recepção de experiências de outros países, mas também dos parâmetros estabelecidos na esfera do sistema internacional (universal e regional) de proteção dos direitos humanos e fundamentais.

Nessa perspectiva, não há como deixar de considerar - dadas as suas consequências para o enfrentamento e equacionamento dos problemas concretos se a liberdade de expressão assume, ou não, uma posição preferencial em relação as demais liberdades e mesmo outros direitos fundamentais, e em que medida tal posição preferencial impacta os processos de ponderação quando se trata de aferir a legitimidade jurídica de restrições à liberdade de expressão em prol da proteção de outros direitos fundamentais e/ou outros bens jurídicos de estatura constitucional.

A importância da discussão em torno do peso relacional da liberdade de expressão é que ela impacta diretamente o modo de enfrentamento dos problemas relativos ao discurso do ódio e de sua interdição. Nesse contexto, por sua vez, assume particular relevo a adoção de uma compreensão mais ou menos restritiva da definição jurídica do discurso de ódio, ou seja, dito de outro modo, a decisão a respeito de quais manifestações podem e quais não podem ser tidas como assim enquadradas e se - e até que ponto - podem ser reprimidas.

Importa sublinhar, nesta quadra, que as diferenças entre as ordens jurídicas no que diz com a posição preferencial da liberdade de expressão em matéria - frise-se - do assim chamado discurso do ódio, chegam a ser significativas, como ocorre, v.g., nos EUA, na Europa, na Alemanha e mesmo no Brasil, em especial quando em causa a negação do holocausto.

No caso dos EUA, consoante já adiantado, a jurisprudência da Suprema Corte tem mantido firme o seu já antigo entendimento no que diz com a interpretação da Primeira Emenda (1791) à Constituição Federal de 1787, que, em regra, proíbe qualquer limitação da liberdade de expressão, assegurando-lhe uma forte posição 
preferencial na arquitetura constitucional e em face de outros direitos e bens constitucionais, atribuindo um sentido muito restritivo ao conceito de discurso do ódio para efeitos de sua interdição e sancionamento ${ }^{10}$.

Assim, nos EUA, mesmo manifestações de natureza inequivocamente contrárias à realidade fática, incluindo a negação do Holocausto, mas também outras como manifestações neonazistas, afirmação da supremacia branca, queima de cruzes em frente a residências de afrodescendentes e mesmo (respeitados alguns pressupostos) a exortação ou apoio a atos de violência concretos e discriminatórios são tidas, em regra, como protegidas pela Primeira Emenda. No entanto, mesmo lá, a liberdade de expressão não assume feições absolutas, visto serem vedadas, em caráter excepcional, manifestações de cunho eminentemente difamatório e calunioso, bem como interdita a incitação à violência ${ }^{11}$.

$\mathrm{Na}$ Alemanha, tal como em termos gerais no ambiente europeu (com destaque para a Carta Europeia dos Direitos Fundamentais (CEDF) e mesmo a jurisprudência do TJUE, mas em especial na jurisprudência da CEDH) ${ }^{12}$, pelo contrário, o conceito de discurso do ódio, como já visto na parte introdutória, é mais amplo e, por via de consequência, maior é a possibilidade de impor limites à liberdade de expressão, como se verifica, por exemplo, com discursos que negam o Holocausto ou que veiculem conteúdo discriminatório ${ }^{13}$.

A título de exemplo, vale referir recente decisão (1 BvR 673/18) de 22 de junho de 2018, do Tribunal Constitucional Federal da Alemanha (TCFA) ${ }^{14}$, que entendeu ser compatível com a Lei Fundamental e com a liberdade de expressão nela consagrada e protegida (artigo $5^{\circ}, 1$ ) a criminalização e consequente punição pela negação do genocídio nacional-socialista, designadamente, no caso concreto objeto do julgamento (com a não admissão para decisão) de reclamação constitucional (Verfassungsbeschwerde) que impugnava decisão que havia condenado a reclamante por ter negado a ocorrência do extermínio levado a efeito no campo de concentração de Auschwitz-Birkenau.

10 Para o caso dos EUA, v., numa perspectiva geral, Zick (2018); sobre o discurso do ódio, v. em especial Waldron (2012). Numa perspectiva comparada - EUA e Alemanha, v. entre outros Brugger (2003. p. 372 e ss). Do mesmo autor, v. também Brugger (2010).

11 Cf. sobre o tema, em especial da relação entre a liberdade de expressão e outros direitos fundamentais, v. aqui também Zick (2018).

${ }^{12}$ V., entre outros, Porras Ramirez (2018, p. 77 e ss). O autor, após uma apresentação geral do tema, destacando que também na Europa (ainda que de modo mais tímido que nos EUA) a liberdade de expressão tem assumido, em regra, uma posição preferencial, demonstra que, no concernente ao problema do discurso do ódio, a definição de seu conteúdo é mais ampla e o sistema de proteção mais rigoroso.

13 Sobre o tema v., na Alemanha (mas também examinando o sistema Europeu (Carta dos Direitos Fundamentais da União Europeia e Convenção Europeia dos Direitos Humanos): Struth (2018).

14 Cf. Deutschland (2018). 
Para o TCFA - aqui em apertadíssima síntese - a difusão consciente de afirmações fáticas comprovadamente inverídicas não contribui para a formação da opinião no contexto público e, portanto, não se encontra protegida pela liberdade de expressão. Ademais disso, a negação do genocídio nacional-socialista extrapola as fronteiras de um embate de ideias pacífico na esfera pública e indica uma afetação da paz social. Assim, o que se percebe - já que tal decisão adere a uma tradição consolidada ao longo da trajetória existencial da corte desde início dos anos 1950 - é que, embora em outros domínios - como se dá com charges, sátiras, exposição de fotografias de personalidades públicas, críticas direcionadas ao governo, políticos, etc. - o TCFA tenha se mostrado progressivamente mais liberal e favorável a uma posição fortalecida da liberdade de expressão, em situações mais sensíveis como a do discurso de ódio e particularmente marcadas pelos atos praticados no período nacional-socialista, manifestações de tal natureza devem ser objeto de reprimenda ${ }^{15}$.

Quando se trata de apresentar o caso do Brasil, embora se verifique uma tendência de gradual fortalecimento da liberdade de expressão, inclusive no sentido de uma posição preferencial, a situação, especialmente no concernente ao discurso do ódio, ainda não está bem definida, quando ao conteúdo da noção, e, por via de consequência, em relação a qual os limites que podem ser impostos às liberdades comunicativas, em particular as liberdades de expressão e reunião.

Note-se que, em um primeiro momento, a lista de direitos fundamentais prevista artigo $5^{\circ}$ da $\mathrm{CF}$, pelo menos numa primeira aproximação e com base no teor literal dos respectivos preceitos, aparentemente, atribui idêntico valor tanto à proteção à intimidade, privacidade, honra e imagem, quanto à liberdade de manifestação de pensamento e de expressão artística, intelectual, científica e de comunicação ${ }^{16}$.

Da leitura desses dispositivos constitucionais, não há - com o devido respeito a posições divergentes -como se identificar uma prioridade necessária de um conjunto de proteções em relação ao outro, na medida em que a previsão constitucional desses direitos fundamentais visa apenas a afirmar - ainda de um modo relativamente indeterminado - a existência desses dois focos de liberdades humanas básicas, as quais não poderão ser abolidas, desprezadas nem gravemente penetradas por outras pretensões jurídicas. Os limites do seu exercício e as situações em que, uma e outra, cederão em sua relevância deverão ainda ser objeto de especificação e de análise casuística.

\footnotetext{
${ }^{15}$ Cf. entre outros, Bethge (2018, p. 195-196).

${ }^{16}$ Art. $50(\ldots)$

IV - é livre a manifestação do pensamento, sendo vedado o anonimato;

IX - é livre a expressão da atividade intelectual, artística, científica e de comunicação, independentemente de censura ou licença;

$X$ - são invioláveis a intimidade, a vida privada, a honra e a imagem das pessoas, assegurado o direito a indenização pelo dano material ou moral decorrente de sua violação;
} 
Por isso, partindo-se dessa exegese constitucional, deve-se iniciar reconhecendo que os dois conjuntos de direitos fundamentais encontram-se, aprioristicamente, em pé de igualdade, na medida em que essas esferas protetivas visam a resguardar e proteger duas instâncias distintas de imensurável valor humano, nenhuma delas, porém, absoluta: uma, com propósito de viabilizar o pleno desenvolvimento espiritual e autônomo de cada indivíduo, no que tange à proteção do plano interno de sua consciência e dignidade, resguardando-o de uma exposição pública desnecessária ou estigmatizante, enquanto que a outra visa a viabilizar o pleno desenvolvimento no plano externo não só de cada indivíduo, por meio da possibilidade desse manifestar, publicamente, a sua visão de mundo, garantindo assim a sua auto expressão - que também representa uma das dimensões da sua dignidade-, como também, por meio do livre fluxo de ideias e opiniões, estabelecer e efetivar o próprio sistema democrático que a nossa Constituição estabelece o qual não se desenvolve sem a possibilidade de externalização de um pluralismo de ideais ${ }^{17}$.

Todavia, mesmo que, em um primeiro momento, a CF assegure um idêntico status protetivo a privacidade e a garantia da liberdade de manifestação e expressão, percebe-se que, em relação à segunda, o texto constitucional entendeu por bem ser mais explícito e detalhista no que se refere aos critérios de controle e de restrição dessa liberdade, tal como se vê das regras constitucionais contidas nos artigos 220 e 221. Isso porque a CF, além de fixar de antemão impedimentos legislativos ( $\S 1^{\circ}$ e $\S 3^{\circ}$ do artigo 220 ), entendeu por bem já prever a proibição categórica à censura ( $\$ 2^{\mathrm{o}}$ do artigo 220$)$, assim como fixar princípios diretivos que deverão guiar a produção publicitária, de rádio e de televisão $\left(\S \S 4^{\circ}, 5^{\circ}\right.$ e $6^{\circ}$ do artigo 220 e artigo 221).

Tal opção constitucional pode ser interpretada como sendo um sinal de que o Constituinte foi mais seletivo no que se refere às restrições que poderão ser aplicadas à liberdade de imprensa, de manifestação de pensamento e de expressão do que foi em relação à proteção da intimidade e da privacidade, a qual deverá contar com uma ponderação a posteriori para identificar as situações de grave e intolerável interferência na esfera de proteção privada. Ou seja, os limites (e consequentes restrições) de tais liberdades já estão, em grande parte, pré-fixadas na Constituição, ao passo que eventuais restrições aos direitos de personalidade foram deixadas para especificação posterior, não só pelo legislador, como pela apreciação equitativa do Judiciário. Essa opção do constituinte de 1988 pode ser interpretada como indicando a escolha constitucional por tratar restrições à liberdade de manifestação e expressão como sendo algo excepcional, exigindo que eventuais restrições adicionais necessitem de um esforço argumentativo diferenciado e mais intenso que consiga justificar a necessidade particular de uma nova limitação ${ }^{18}$.

${ }^{17}$ Cf. Sarlet (2018, p. 77).

${ }_{18}$ Sarlet (2018, p. 77). 
É nessa perspectiva que se pode afirmar que, mediante uma interpretação sistemática - aliada ainda ao fato de ser a liberdade de expressão e informação indispensável (e mesmo estruturante) a um regime democrático - a CF assegurou a tais liberdades uma posição (relativa) preferencial em face dos direitos de personalidade, que pode ser compreendida como uma preferência prima facie. Aliás, esse tem sido - ao menos até o momento - o entendimento que tem prevalecido na literatura nacional (embora a existência de significativo dissenso) ${ }^{19}$ e na jurisprudência, em especial nos Tribunais Superiores, com destaque aqui para o STF, ao menos em se levando em conta os principais casos julgados nos últimos anos, tem apontado para uma posição preferencial da liberdade de expressão e informação.

Dentre os casos julgados pelo STF envolvendo a liberdade de expressão e indicando sua posição preferencial, podem ser colacionados a declaração da não recepção, por incompatibilidade com a CF, da antiga Lei de Imprensa elaborada no curso do regime militar, quando o Relator, Ministro Carlos Britto, afirmou que a liberdade de expressão assume uma posição quase absoluta e apenas pode ser objeto de limitação nos casos expressamente estabelecidos pela $\mathrm{CF}$, designadamente o direito à indenização e o direito de resposta ${ }^{20}$. Da mesma forma chamam a atenção dois outros casos, o assim chamado caso "marcha da maconha", no qual o STF entendeu que uma manifestação pública e coletiva em prol da legalização do consumo da maconha não poderia ser enquadrada no tipo penal da apologia ao crime $^{21}$. Mais recentemente, merecem referência os casos das biografias não autorizadas, no qual o STF decidiu ser inconstitucional a existência de prévia autorização do biografado ${ }^{22}$, bem como o julgado que traçou uma diferenciação, no que diz com o processo eleitoral, entre críticas veiculadas mediante sátiras e charges e manifestações de humor em geral e as assim chamadas fake news, liberando as primeiras e vedando as últimas ${ }^{23}$.

Todavia, nenhum dos casos nominados envolvia a veiculação de informações (manifestações) evidentemente inverídicas ou de caráter em si ofensivo (injúria, difamação e mesmo calúnia), nem mesmo situações em que se possa afirmar com convicção que tenha se tratado de um exemplo do assim chamado discurso do ódio. Em especial no caso do último, não há como deixar de referir o principal precedente do STF, de 2003, envolvendo a confirmação da condenação criminal por racismo de autor e editor de obra que negava o holocausto judeu durante a segunda grande guerra mundial, justamente não sustenta a tese da posição preferencial da

\footnotetext{
${ }^{19}$ Em caráter ilustrativo destacam-se aqui, em favor da posição preferencial, Barroso (2005, p. 103), bem como, mais recentemente, Sarmento (2018).

${ }^{20}$ Brasil (2009). ADPF 130

${ }^{21}$ Brasil (2011). ADPF 187

22 Brasil (2015). ADI 4.815

${ }^{23}$ Brasil (2018). ADI 4.451
} 
liberdade de expressão, ainda que três Ministros tenham encaminhado voto divergente ${ }^{24}$.

É claro, por outro lado, que a negação do holocausto (já há tempo criminalizada no Brasil) representa um caso muito especial e impactante, a justificar aqui um entendimento diferenciado, mas ao mesmo tempo também se sabe que a depender da prevalência que se der à liberdade de expressão, como é o caso dos EUA, a solução poderia ser diversa.

Por sua vez, há que frisar, também não resulta possível afirmar, de modo categórico, que no caso específico do discurso do ódio, o STF tenha assumido uma posição preferencial da liberdade de expressão nos outros (poucos) julgados sobre a matéria, o que será analisado logo mais adiante.

À vista da breve apresentação sobre como é compreendida e manejada, em termos gerais, mas em especial no que diz com sua posição mais ou menos privilegiada nas ordens jurídicas norte-americana, alemã, europeia e brasileira, a relação entre a liberdade de expressão e outros direitos fundamentais, com destaque para os direitos de personalidade, e cientes de que se trata de questão prejudicial ao exame do problema específico do discurso do ódio, remetemos ao próximo segmento para uma aproximação mais detida desse aspecto, que, de resto, é o objeto precípuo do presente trabalho.

Seja onde for, eventual limitação à liberdade de expressão, em especial a determinados discursos, tem sido justificada com base no seu impacto sobre os direitos de personalidade e o seu conteúdo em dignidade humana (v.g. os direitos à privacidade, honra, imagem, nome, entre outros), mas também quando se trata de conter a segregação, a discriminação de toda a natureza bem como incitação à violência, atingindo grupos vulneráveis e mesmo comprometendo a própria democracia.

De outra parte, o maior ou menor peso atribuído à liberdade de expressão numa determinada ordem jurídica e a extensão dada ao conteúdo do assim chamado discurso do ódio assume, como já adiantado, particular relevância também no ambiente da Internet, o que será a seguir examinado na perspectiva europeia, em especial no que diz com o marco normativo da Convenção Europeia dos Direitos Humanos (ConvEDH) e a jurisprudência da CEDH, mas também à luz do GNEA e do marco normativo e jurisprudencial (aqui com destaque para o STF) brasileiro.

\section{O DISCURSO DO ÓDIO E O SEU ENFRENTAMENTO NA ESFERA DA INTERNET: ALGUMAS NOTAS EM TORNO DA JURISPRUDÊNCIA RECENTE DA CEDH, DO GNEA E DA JURISPRUDÊNCIA DO STF}

No que toca ao ambiente digital, foco da nossa atenção, destaca-se, na Europa, a jurisprudência da $\mathrm{CEDH}$, aqui representada pelo julgamento do caso Belkacem $v$.

${ }^{24}$ Brasil (2003) HC 84292/RS. 
Belgium, de 27.06.201725. Em apertada síntese, o caso versava sobre a legitimidade (na perspectiva da ConvEDH) da condenação criminal (em 2012) à pena de dois anos de prisão do cidadão belga Belkacem, líder e porta-voz da organização "Sharia4Belgium", pelo fato de ter postado na plataforma do YouTube, vídeos de caráter ofensivo, e incitando à discriminação de pessoas não-mulçumanas, tendo como alvo principal o então Ministro da defesa daquele país.

Note-se que nos referidos vídeos foi deflagrada uma convocação dos internautas para a dominação e para a conflagração de atos de combate alicerçados na apologia da jihad e da sharia, tendo Belkacem sido processado com fundamento na Belgium's Anti-Discrimination Law de 2007. De acordo com a Corte de Antuérpia, restara manifesto o caráter intencional, explícito e reiterado das ofensas e incitações à discriminação e violência, aplicando, além da pena restritiva de liberdade, multa no valor de quinhentos e cinquenta euros. A decisão condenatória, salvo quanto à revisão do tempo de prisão, foi mantida em grau de apelação (2013).

Em face de recurso individual interposto em abril de 2014, alicerçado na negativa dos atos de incitamento e do discurso de ódio, bem como com arrimo no seu direito à liberdade de expressão, assegurado pelo artigo 10 da ConvEDH, a $\mathrm{CEDH}$, entendeu configurado o abuso no exercício dessa liberdade, por conta do caráter ofensivo, discriminatório e violento do conteúdo dos vídeos postados pelo recorrente, direcionado a todos não-muçulmanos, aplicando ao caso concreto o disposto no artigo 17 da referida Convenção. De acordo com a CEDH, o conteúdo dos vídeos e as respectivas manifestações de Belkacem configuram ataque aos valores da tolerância, da paz social e da não discriminação que subjazem e permeiam a ConvEDH. Em especial no tocante às referências de Belkacem sobre a Sharia, a Corte reiterou seu entendimento - mencionado na parte introdutória - de que a propagação na internet de discursos apologéticos convocando para atos de violência pode ser classificada como discurso do ódio e que, por tal razão, cada Estado signatário da Convenção tem o direito de se opor a movimentos de tal natureza baseados em fundamentalismo religioso. Disso resulta que a legislação belga, com base na qual se deu o juízo condenatório de Belkacem, é plenamente compatível com a ConvEDH, a jurisprudência da Corte e as recomendações do Conselho da Europa, destinadas a combater o incitamento ao ódio, à discriminação e à violência.

Note-se que embora não exista uma diretiva ou regulamento específico voltado ao combate do discurso do ódio na Internet no âmbito da normativa da União Europeia, foram criados alguns instrumentos de para tal efeito. Destacam-se aqui as medidas da Comissão para o combate do racismo e da intolerância do Conselho da Europa, Estrasburgo, como é o caso de um código de conduta emitido em

25 A respeito da decisão, conferir: http://hudoc.echr.coe.int/eng-press?i=003-5795519-7372789. Acesso em: $1^{\circ}$ out. 2018. Para conferir a decisão na íntegra, v. European Union (2017). 
31.05.2016, em parceria com Facebook, Twitter, YouTube, Google e Microsoft ${ }^{26}$ e uma recomendação sobre o tratamento dispensado a contetúdos ilegais na internet, de 26.04.2018. ${ }^{27}$

Portanto, muito embora não exista normativa europeia específica voltada ao combate do discurso do ódio na Internet, as instituições europeias tem estado atentas ao problema e promovido algumas medidas concretas no sentido do seu enfrentamento, destacando-se aqui a retratada decisão da $\mathrm{CEDH}$, que - e é esse o ponto a ser aqui sublinhado - chancelou a possibilidade dos Estados submetidos à sua jurisdição de, na esfera de sua margem de apreciação, tomarem medidas significativas, como é o caso da criminalização do discurso do ódio.

Por outro lado, isso não significa que a $\mathrm{CEDH}$ tenha, mesmo na decisão aqui retratada, aberto as portas para todo e qualquer tipo de medida limitativa da liberdade de expressão ou mesmo sufragado uma interpretação demasiado elástica do conceito de discurso do ódio para tal efeito. Já por isso - mas também na perspectiva das ordens jurídicas nacionais, em especial dos catálogos constitucionais de direitos fundamentais - cada intervenção no âmbito da liberdade de expressão deve ser objeto de criterioso exame quanto a sua legitimidade convencional e constitucional.

Portanto, é nesse contexto que se situa a polêmica em torno do assim chamada Netzwerkdurchsetzungsgesetz (GNEA) aprovado pelo Parlamento Alemão, em 01.09.2017, com o escopo de coibir e reprimir discursos ofensivos, discriminatórios e a incitação à violência na Rede ${ }^{28}$. Tal legislação foi o resultado de um movimento de reação ao crescimento exponencial - em especial (mas não só) a partir da política migratória alemã que atraiu, apenas nos últimos anos, mais de um milhão de migrantes, a grande maioria oriunda da Síria - do fluxo de manifestações que configuram um discurso do ódio na internet, medida que, em princípio, guarda consonância com a tradição alemã mais refratária ao discurso do ódio, mas também mais sensível em reação a ofensas em geral aos direitos de personalidade.

Mas, em que pese a motivação em si legítima da lei, são muitas as críticas que têm atraído, inclusive na fase de sua elaboração e discussão no Parlamento, mas também no que diz com a sua aplicação, assumindo particular relevância a controvérsia em torno de sua compatibilidade com a Lei Fundamental alemã, mas também com a CEDH e a CEDF, naquilo em que veicula restrições à liberdade de expressão no ambiente das redes sociais ${ }^{29}$.

\footnotetext{
26 V. European Union (2018).

27 Para efetuar o download do texto da recomendação: https://ec.europa.eu/digital-singlemarket/en/news/commission-recommendation-measures-effectively-tackle-illegal-contentonline. Acesso em: 25 out. 2018.

28 Para ler o conteúdo da lei: https://www.buzer.de/s1.htm?g=Netzwerkdurchsetzungsgesetz++NetzDG\&f=1. Acesso em: $1^{\mathfrak{o}}$ out. 2018.

29 Sobre o tópico, v. por todos, apresentando uma síntese da controvérsia e remetendo à bibliografia mais atual e relevante, mas pessoalmente adotando um entendimento substancialmente favorável,
} 
Não sendo viável explorar com maior detalhamento o conteúdo da lei e a miríada de suas repercussões e dos questionamentos que suscita, limitamo-nos a colacionar alguns dos principais aspectos e que objetivam viabilizar um maior controle em relação ao exercício do discurso do ódio e mesmo a sua interdição.

Assim, é de se enfatizar, de plano, que a nova lei exigiu a implantação de medidas de segurança mais claras e rígidas quanto aos conteúdos lesivos e potencialmente ilegais, possibilitando à cidadania um amplo controle do material postado.

Quanto aos seus destinatários, a teor do seu $\S 1^{\circ}$, 1 e 2, a nova legislação, tem por destinatários a empreendimentos que promovem plataformas sociais com fins lucrativos e com mais de dois milhões de usuários na Alemanha. Vale notar, todavia, que a lei estabeleceu diferenças em relação aos diversos tipos de provedores, não incidindo em relação às plataformas voltadas para a troca de mensagens e de e-mails. Da mesma forma, não são abarcadas plataformas destinadas a veicular conteúdos jornalísticos e redacionais. ${ }^{30}$

Já no concernente ao seu objeto, a nova lei determina sejam eliminados e bloqueados conteúdos ilícitos postados nas mídias sociais destinatárias. De acordo com o $\S 1^{\circ} 3$, são tidos como ilícitos todos os conteúdos que correspondam aos fatos típicos previstos em ao todo 23 dispositivos do Código Penal alemão, como, por exemplo, que envolvem atentados contra a segurança estatal e a ordem pública, mas também delitos contra os direitos de personalidade ${ }^{31}$.

Nessa perspectiva o GNEA estabeleceu uma linha divisória entre atos que configuram crime (ilícitos penais) de natureza diversa na rede (como, v.g., a fraude), a assim chamada criminalidade do ódio e as fake News. Além disso, convém sublinhar, não ficou claro se para restar configurada a ilicitude de um determinado conteúdo, necessário que o provedor verifique se implementado o suporte fático

Lang (2018, p. 225). Sustentando a incompatibilidade substancial, em vários pontos, do GNEA, com a Lei Fundamental e a Convenção Europeia, v., por todos, o parecer de Spindler (2017).

30 "(1) This Act shall apply to telemedia service providers which, for profit-making purposes, operate internet platforms which are designed to enable users to share any content with other users or to make such content available to the public (social networks). Platforms offering journalistic or editorial content, the responsibility for which lies with the service provider itself, shall not constitute social networks within the meaning of this Act. The same shall apply to platforms which are designed to enable individual communication or the dissemination of specific content. (2) The provider of a social network shall be exempt from the obligations stipulated in sections 2 and 3 if the social network has fewer than two million registered users in the Federal Republic of Germany."

31 "(3) Unlawful content shall be content within the meaning of subsection (1) which fulfils the requirements of the offences described in sections 86, 86a, 89a, 91, 100a, 111, 126, 129 to 129b, 130, 131, 140, 166, 184b in connection with 184d, 185 to 187, 201a, 241 or 269 of the Criminal Code and which is not justified." Observação: o § 201a foi incluído na versão aprovada pelo parlamento e não estava comtemplado na tradução utilizada. 
subjetivo e objetivo e a ilicitude ou se basta a presença do suporte fático objetivo e a ilicitude ${ }^{32}$.

Nesse sentido, o GNEA estabeleceu uma obrigação para os empreendimentos que oferecem plataformas sociais de criar um procedimento transparente e eficaz e permanentemente disponível e apto a ser facilmente compreendido e manejado por parte dos usuários, assegurando que os provedores tenham condições de acessar com rapidez a reclamação e tomar providências imediatas no sentido de eliminar ou bloquear os conteúdos ilícitos impugnados $(\S 3,1) .^{33}$

De acordo com o $\S 3,2$, no 1 da Lei, os provedores de rede social também têm a obrigação de disponibilizar um processo que possibilite o imediato conhecimento e decisão acerca da eliminação ou bloqueio do acesso ao conteúdo supostamente ilícito ${ }^{34}$, implementando uma espécie de procedimento do notice and take down, previsto originalmente nos artigos 14 e 15 da Diretiva 2000/31 do Parlamento Europeu, regulando o e-commerce ${ }^{35}$.

${ }^{32}$ Holznagel (2017, p. 614 e ss).

33 "(1) The provider of a social network shall maintain an effective and transparent procedure for handling complaints about unlawful content in accordance with subsections (2) and (3). The provider shall supply users with an easily recognisable, directly accessible and permanently available procedure for submitting complaints about unlawful content."

34 " (2) The procedure shall ensure that the provider of the social network: 1. takes immediate note of the complaint and checks whether the content reported in the complaint is unlawful and subject to removal or whether access to the content must be blocked,"

${ }^{35}$ Cf. Holznagel (2017, p. 614-615). "Article 14. Hosting. 1. Where an information society service is provided that consists of the storage of information provided by a recipient of the service, Member States shall ensure that the service provider is not liable for the information stored at the request of a recipient of the service, on condition that: (a) the provider does not have actual knowledge of illegal activity or information and, as regards claims for damages, is not aware of facts or circumstances from which the illegal activity or information is apparent; or (b) the provider, upon obtaining such knowledge or awareness, acts expeditiously to remove or to disable access to the information. 2. Paragraph 1 shall not apply when the recipient of the service is acting under the authority or the control of the provider. 3. This Article shall not affect the possibility for a court or administrative authority, in accordance with Member States' legal systems, of requiring the service provider to terminate or prevent an infringement, nor does it affect the possibility for Member States of establishing procedures governing the removal or disabling of access to information. Article 15. No general obligation to monitor. 1. Member States shall not impose a general obligation on providers, when providing the services covered by Articles 12, 13 and 14, to monitor the information which they transmit or store, nor a general obligation actively to seek facts or circumstances indicating illegal activity. 2. Member States may establish obligations for information society service providers promptly to inform the competent public authorities of alleged illegal activities undertaken or information provided by recipients of their service or obligations to communicate to the competent authorities, at their request, information enabling the identification of recipients of their service with whom they have storage agreements." European Union (2000) on certain legal aspects of information society services, in particular electronic commerce, in the Internal Market ('Directive on electronic commerce'). 
Outrossim, as mídias sociais devem informar imediatamente os usuários e reclamantes de toda e qualquer providência tomada, fundamentando a sua decisão $\left(\S 3,2\right.$, no 5, do GNEA). ${ }^{36}$ Note-se que, como reação a tal previsão legal, os grandes atores da Internet já iniciaram a instituir mecanismos para atender a demanda. Assim, em caráter ilustrativo, verifica-se que o Google criou um formulário específico para fins de delação ${ }^{37}$, o Twitter adicionou novas funções às contas dos usuários ${ }^{38}$, enquanto o Facebook criou uma página específica na qual a vítima deve selecionar dentre as opções previamente disponibilizadas e anexar o screenshot da postagem ${ }^{39}$.

Um primeiro ponto a ser destacado, diz respeito ao fato de que de acordo com a lei qualquer usuário pode denunciar a ocorrência do discurso do ódio, de tal sorte que é possível afirmar que se procurou estabelecer uma espécie de alargado controle social sobre as mídias sociais pelos seus próprios usuários. Além disso, de acordo com o seu $\S 3,2$, nos. 2 e 3 a lei estabeleceu o prazo de vinte e quatro horas após a denúncia para a plataforma deletar ou bloquear o acesso a postagem quando a ilicitude da postagem for evidente, e, em casos mais complexos, ampliou o prazo para sete dias, prazo este que poderá ser excedido, quando: “a) a decisão relativa à ilegalidade do conteúdo depende da falsidade de alegação fática ou é claramente dependente de outras circunstâncias fáticas. Em tais casos, a mídia social pode conceder ao usuário a possibilidade de responder à reclamação antes de proferir a decisão; b) a rede social refere a decisão submete a decisão sobre a ilegalidade a uma reconhecida instituição no âmbito da autorregulação, no prazo de sete dias a contar do recebimento da reclamação, concordando em acatar a decisão de tal instituição;

Para o caso de descumprimento, foram previstas penas de multa de até cinco milhões de euros $(\S 4,2){ }^{40}$

\footnotetext{
36 " 5 . immediately notifies the person submitting the complaint and the user about any decision, while also providing them with reasons for its decision,"

${ }^{37}$ No Google News há o instrumento "Enviar feedback" no qual é necessário enviar uma "captura de tela". Para mais detalhes consulta o site da rede social: $<$ https://news.google.com/ $>$. Acesso em: 26.10.2018.

38 Com relação ao Twitter consultar por exemplo: <https://help.twitter.com/en/safety-andsecurity/report-abusive-behavior>. Acesso em: 26.10.2018.

${ }^{39}$ No Facebook acima das notícias, onde tem três reticências aparece a opção "Give Feedback on This Post". Para mais detalhes consulta o site da rede social: $<$ https://pt-br.facebook.com/>. Acesso em: 26.10.2018.

40 " (2) In cases under subsection (1) numbers 7 and 8, the regulatory offence may be sanctioned with a regulatory fine of up to five hundred thousand euros, and in other cases under subsection (1) with a regulatory fine of up to five million euros. Section 30(2) sentence 3 of the Act on Regulatory Offences shall apply."
} 
A Lei também estabelece uma obrigação de as mídias sociais elaborarem e publicarem um relatório semestral sobre as reclamações recebidas e respectivas providências envolvendo a impugnação de conteúdos tido como ilícitos (§ 2$)^{41}$.

Mas, consoante já adiantado, diversos dispositivos da lei têm sido questionados quanto à sua legitimidade constitucional - em face da Lei Fundamental da Alemanha -, ademais de eventual incompatibilidade com o marco Europeu em termos de liberdade de expressão e outros direitos humanos e fundamentais, sejam consagrados na ConvEDH, sejam positivados na CEDF.

Para além da alega inconstitucionalidade formal da nova legislação, que aqui não será enfrentada, inclusive por isoladamente arguida ${ }^{42}$, seguem os pontos mais disputados, que aqui não são apresentados em ordem de relevância.

Uma primeira objeção diz respeito ao fato de que caberá em um primeiro momento às plataformas deliberar sobre o potencial ofensivo da postagem, gerando, uma abertura à instituição de censura privada e uma privatização da execução da lei ${ }^{43}$.

Outro aspecto relevante diz respeito ao fato, alegado por alguns, o Estado alemão passaria, de forma indireta a aceitar e, em certa medida, até a incentivar a política de vigilância e de monitoramento geral efetuada nas redes sociais, embora não tenha expressamente exigido das plataformas esse tipo de procedimento ${ }^{44}$.

Da mesma forma, questiona-se a amplitude do elenco de conteúdos que podem ser considerados ilícitos, tendo em conta a quantidade de tipos penais listados para tal efeito inclusive sem maior fundamentação, propondo-se, quanto a isso, um ajuste corretivo de modo a reduzir as hipóteses a algumas figuras essenciais ${ }^{45}$.

Ademais disso, os prazos fixados pelo legislador para a tomada de providências pelos provedores das plataformas sociais (eliminação ou bloqueio) são demasiado exíguos para que se possa examinar de modo adequado a sua efetiva ilicitude. Note-se, ainda, que a maioria dos tipos penais elencados demandam uma interpretação à luz das exigências da liberdade de expressão, o que, por sua vez, é, em muitos casos, controverso e demanda uma cuidadosa avaliação, em especial levando em conta que de acordo com a jurisprudência do TCFA nem todo conteúdo de caráter ofensivo (sátira, crítica, etc.) configura um abuso no exercício da

\footnotetext{
41 "(1) Providers of social networks which receive more than 100 complaints per calendar year about unlawful content shall be obliged to produce half-yearly German-language reports on the handling of complaints about unlawful content on their platforms, covering the points enumerated in subsection (2), and shall be obliged to publish these reports in the Federal Gazette and on their own website no later than one month after the half-year concerned has ended. The reports published on their own website shall be easily recognisable, directly accessible and permanently available. (2) The reports shall cover at least the following points: [...]"

${ }^{42}$ Nesse sentido, sustentando tal ilegitimidade formal, v., por todos, Gersdorf (2017, p. 439 e ss).

${ }^{43}$ Sobre o ponto v., por todos, Schröder (2017, p. 309-331).

${ }^{44}$ Cf., por todos, Spindler (2017).

${ }^{45}$ Holznagel (2017, p. 623).
} 
liberdade de expressão e, nesse sentido, um ilícito passível de sanção ${ }^{46}$. O mesmo, aliás, se verifica quando se trata se aferir se algum conteúdo configura um atentado contra a segurança estatal e a ordem pública, razão pela qual aqui também questionável se um ator privado, ainda mais em prazo tão curto (24 horas quando se tratar de conteúdo manifestamente ilícito, seja o que isto queira dizer, valeria acrescentar) pode ele mesmo levar a efeito tal julgamento ${ }^{47}$.

Outrossim, no concernente aos prazos legais para a remoção ou bloqueio de um conteúdo ilícito a própria lei, como já referido acima, prevê a possibilidade de exceções em que não incidem tais prazos, além de necessária a notificação, assegurando a possibilidade de manifestação do usuário. Se com isso restam afastadas de modo satisfatório as objeções referidas, não há como aqui avançar em relação ao ponto.

Após a apresentação, em traços gerais, do modelo atualmente vigente na Alemanha e (também em construção) na esfera da União Europeia, mas em especial no que diz com o âmbito de aplicação da ConvEDH e jurisprudência da CEDH, é o caso de tecer algumas considerações sobre o caso do Brasil, em especial à luz da jurisprudência do STF em matéria de discurso do ódio na Internet.

Como já adiantado, tanto parte significativa da literatura jurídica quanto em especial a evolução da prática decisória do STF, têm fortalecido a posição relacional da liberdade de expressão na arquitetura constitucional, atribuindo-lhe uma posição prima facie preferencial em face de outros direitos fundamentais. Da mesma forma consoante sinalizado, não é possível - na atual quadra - extrair uma posição minimamente consolidada, no que diz com a definição de discurso do ódio praticada pelo STF, em especial, se de fato compatível com a reiteradamente afirmada posição preferencial da liberdade de expressão.

O caso da negação do holocausto por si só - pelo menos em princípio e em comparação com a orientação dominante nos EUA - já poderia indicar justamente o contrário, ou seja, que a liberdade de expressão não assume uma condição privilegiada dentre o extenso rol de liberdades e direitos fundamentais consagrados na CF. Quando se leva em conta a jurisprudência mais recente do STF sobre os limites da liberdade de expressão, a impressão de que não há ainda suficiente clareza quanto a posição da Corte no concernente ao conteúdo do assim chamado discurso de ódio, como manifestação abusiva da liberdade de expressão, se torna ainda mais acentuada. O que se pode, contudo, arriscar, afirmar que a tendência da prática decisória da Suprema Corte brasileira é no sentido de privilegiar um conceito pelo menos significativamente mais abrangente do que o adotado nos EUA, embora possivelmente mais restrito do que o praticado pela CEDH. Para ilustrar tal assertiva, colacionamos três julgados recentes.

${ }^{46}$ Holznagel (2017. p. 622-623).

${ }^{47}$ Holznagel (2017, p. 623-624). 
No primeiro caso, designadamente no Inquérito 4694/DF, Relator Ministro Marco Aurélio, julgamento em 28.08.2018, a Primeira Turma do STF rejeitou denúncia contra parlamentar que, durante uma palestra, teria se manifestado de modo discriminatório e negativo sobre quilombolas, indígenas, refugiados, mulheres e LGBTs (lésbicas, gays, bissexuais, travestis, transexuais e transgêneros). Para o Colegiado, não restou demonstrado o conteúdo discriminatório das declarações, agasalhadas tanto pela liberdade de expressão quanto pela imunidade parlamentar prevista no artigo 53, da CF.

No que diz com a liberdade de expressão, para a maioria dos Ministros o discurso do acusado no processo criminal, no tocante aos quilombolas, embora tenha veiculado posição de superioridade, não objetivou instigar atos de repressão, dominação e eliminação, não se revestindo de caráter discriminatório. Ainda de acordo com a posição da maioria, o interesse na extinção ou redução das reservas indígenas ou terras ocupadas por quilombolas, não se confunde com o intento de eliminação de tais minorias. Além disso, mesmo o fato de o parlamentar acusado ter se valido da expressão arroba, referindo-se ao peso dos quilombolas, não pode ser considerado como manifestação de caráter desumanizador, mas sim, uma forma infeliz de se afirmar que determinada pessoa se encontra acima do peso tido como normal.

Também no concernente às manifestações do parlamentar relativamente aos imigrantes, o colegiado da nossa Suprema Corte entendeu que não houve extrapolação do que se poderia considerar uma crítica à política de imigração governamental, visto que além de não terem sido veiculadas exortações a condutas xenófobas, o acusado afirmou não fazer distinção no concernente à origem estrangeira do imigrante, mas sim, em geral a todos os imigrantes.

Ainda nesse contexto, calha destacar que restou vencido o Ministro Roberto Barroso, que recebeu a denúncia em parte no concernente às manifestações do acusado em relação aos quilombolas, afrodescendentes e homossexuais, vencida também a Ministra Rosa Weber, que, contudo, acompanhou a divergência apenas no tocante às afirmações do acusado direcionadas aos quilombolas.

Nessa quadra, como se pode perceber sem maior dificuldade, já é possível afirmar que no julgamento ora sumariamente apresentado, o STF manteve sua jurisprudência favorável a uma posição preferencial, muito embora o Ministro Roberto Barroso (acompanhado, em parte, pela Ministra Rosa Weber), tenha votado pelo recebimento da denúncia. Tal circunstância, pelo menos numa primeira leitura, pode significar uma parcial alteração da sua enfática defesa da liberdade de expressão, mas também - e nos soa como sendo a exegese mais adequada (embora seja apenas o próprio Roberto Barroso quem possa esclarecer isso) - sugere a busca de manter uma coerência interna entre a defesa da posição preferencial da liberdade de expressão e a posição igualmente firme (já mesmo antes de se tornar Ministro do STF) no tocante ao reconhecimento e proteção dos direitos das minorias. 
Outro julgado que não pode deixar de ser aqui colacionado, diz respeito à ADI 2.566/DF, Relator originário Ministro Alexandre de Moraes, Redator para o Acórdão Ministro Edson Fachin, julgada em 16.05.2019. Em causa esteve a apreciação de pedido de declaração de inconstitucionalidade do artigo $4^{\circ}$, $\S 1^{\circ}$, da Lei 9.612/1998, de acordo com o qual, é proibida a prática de proselitismo (isto é, a transmissão de discursos voltados à conversão de pessoas a determinada doutrina, religião, seita, etc.), no âmbito dos meios comunitários de radiodifusão. A decisão, proferida por maioria, acabou sendo protagonizada pelo Ministro Edson Fachin, que sustentou a tese da inconstitucionalidade por afronta aos termos do artigo $5^{\circ}$, IV, VI e IX, bem como artigo 220, ambos da CF. De acordo com o Ministro, invocando precedentes do próprio STF, inclusive em matéria de liberdade de expressão religiosa, tal liberdade abarca também discursos de cunho persuasivo, ademais da agitação de argumentos críticos, devendo ser assegurado um debate público informado marcado pela livre divulgação e troca de ideias. Em especial, ainda segundo Redator do Acórdão, aplica-se na hipótese o disposto pela Corte no julgamento do RHC 134.682/BA, designadamente, o entendimento de que é da essência das religiões que assumem a pretensão de universais, o discurso de natureza proselitista, de tal sorte que a sua proscrição seria incompatível com o núcleo essencial da liberdade religiosa.

Note-se que neste último caso, onde em causa o proselitismo religioso (mas não incitações à violência física ou moral em relação a outras religiões e seus adeptos), novamente a posição majoritária do colegiado do STF que apreciou a matéria guardou estrita aderência com a por ora dominante (em que pese algumas importantes variações entre os julgadores) da posição preferencial da liberdade de expressão. Além disso, ambos os casos ora referidos, alinham-se com uma noção como já adiantado - mais generosa de discurso do ódio do que a norte-americana, mas mais restritiva do que a praticada à luz da Convenção Europeia dos Direitos Humanos.

\section{CONSIDERAÇÕES FINAIS}

Ainda que não se possa (e nem se pretenda) aqui inventariar todas as possíveis observações e conclusões relativamente ao tema objeto do presente texto, é possível sumariar alguns pontos que parecem centrais.

Uma primeira nota que se impõe, é que o tema da liberdade de expressão e seus limites segue sendo e possivelmente com cada vez maior expressão, altamente sensível e em larga medida vinculado tanto ao direito positivo (internacional, constitucional, infraconstitucional) de cada ordem jurídica, mas em especial às concepções dominantes de democracia, tolerância e liberdade em termos gerais.

De todo modo, em que pese as evidentes diferenças entre os modelos norteamericano, europeu (no sentido da União e Comunidade Europeia), alemão e brasileiro, em todas as respectivas ordens jurídicas, o discurso do ódio é proibido e 
passível de sancionamento, variando - com consequências concretas diferenciadas - o que se entende por discurso do ódio.

Da mesma forma variam os meios pelos quais as diversas ordens jurídicas (instâncias internas e entidades internacionais - e mesmo supranacionais) regulam o discurso do ódio, inclusive sem que existam, em muitos casos, prescrições constitucionais e legais expressas e especificamente voltados a tal fim, o que - é preciso frisar - não define por si só a legitimidade jurídica e acima de tudo a eficácia e efetividade de tais normativas.

Assim, tomando-se por parâmetro os alvos da comparação aqui levada a efeito, apenas a Alemanha, mediante a aprovação do GNEA, adotou - por ora - uma legislação especificamente voltada para a regulação das mídias sociais, sem prejuízo de todo o restante do seu manancial jurídico disponível e aplicável a tais meios de comunicação e aos demais. Isso, por sua vez, por si só - a não ser mediante um adequado monitoramento de tais medidas - não assegura a sua adequação e efetividade, assim como não resolve uma série de outros problemas.

Com isso, todavia, não se está a dizer que a regulação do conteúdo da manifestação (expressão) do pensamento na internet seja dispensável e nem completamente inútil por ineficaz, muito embora também existam os que assim se posicionam. Igualmente segue em aberto em que medida se deve aderir a um modelo mais forte de regulação estatal (e eventualmente também pelos órgãos internacionais), investir na assim chamada autorregulação regulada ou simplesmente dar pleno espação à autorregulação.

É nesse contexto que a recente legislação alemã pode nos oferecer pelo menos algumas pistas.

Assim, pese as diversas objeções articuladas em relação a uma série de disposições do GNEA, a nova legislação, mesmo exigindo alguns ajustes e uma interpretação conforme aos direitos humanos e fundamentais, com destaque para a liberdade de expressão, é de ser, em termos gerais, bem recebida, inclusive pelo fato de que, em termos gerais, guardar compatibilidade e dar concretude à orientação normativa (ainda na forma de soft law) e aos enunciados da CEDH no caso Belkacem v. Belgium.

Particularmente bem-vinda é a criação de um modelo de controle social alargado exercido pelos próprios usuários das mídias sociais, desde que, é claro, não implique em meio de censura (inclusive privada) e de silenciamento da liberdade de expressão na rede, como, em parte, é preciso reconhecer, já se está verificando em alguns ambientes, o que, aqui, não há como aprofundar, mas deve ser referido.

Além do mais, o que o legislador alemão buscou instituir, foi um modelo de compliance, que, em grande medida, incorpora medidas relativas ao apagamento e bloqueio de determinados conteúdos de natureza ilícita já existente, avançando 
no tocante aos instrumentos destinados a tornar efetivas tais medidas, seja por indução, seja mediante sancionamento ${ }^{48}$.

$\mathrm{O}$ que se arrisca aqui a afirmar, é que em especial quando se trata de atores sociais poderosos do ponto de vista tecnológico e econômico, a ausência de regulação do discurso do ódio e a falta de medidas minimamente eficazes para a sua inibição e sancionamento, implica, como já referido, violação dos deveres de proteção estatais na esfera das relações privadas e em relação aos direitos de personalidade, mas acima de tudo da dignidade da pessoa humana, tal como solenemente enunciado no artigo $1^{\circ}$ da Lei Fundamental ${ }^{49}$ e no artigo da CEDF ${ }^{50}$.

Outrossim, é preciso considerar, como já adiantado, o melhor caminho não é o de uma regulação fechada, mas sim - e aqui já adiantamos o nosso entendimento a respeito do tema - o de uma assim designada autorregulação regulada ${ }^{51}$, tal como estabelecido (em que pese os pontos a serem corrigidos), é preciso seja aqui destacado, ainda que não se trate de algo que aqui possa ser desenvolvido.

Por outro lado, eventuais medidas tomadas com esse objetivo não podem implicar violação, por conta de uma intervenção juridicamente ilegítima na esfera de proteção de outros direitos humanos e fundamentais, como é o caso, em primeira linha, da liberdade de expressão e de informação, à qual deve ser assegurada uma posição de proeminência.

Assim, o que se deve poder esperar é que, a partir dos exemplos da decisão da $\mathrm{CEDH}$ no caso Belkacen vs. Belgium, e do exemplo (em que pese os seus pontos polêmicos e eventualmente carentes de correção) do GNEA, outras medidas sejam levadas a efeito para pelo menos reduzir a quantidade e a gravidade das consequências do discurso do ódio na internet.

Todavia, considerando a ausência de fronteiras que caracteriza o ambiente digital e as dificuldades técnicas de levar a efeito um controle mais rígido com base num modelo de natureza sancionatório, a maior aposta deve ser feita na esfera preventiva. Apenas a inclusão digital (incluindo a capacitação para o uso responsável da internet) e a difusão de uma cultura do respeito e da tolerância, bem como eventualmente a criação de um Pacto Internacional para a Proteção dos

\footnotetext{
${ }^{48}$ Holznagel (2017, p. 622 e ss).

49 "(1) Human dignity shall be inviolable. To respect and protect it shall be the duty of all state authority. (2) The German people therefore acknowledge inviolable and inalienable human rights as the basis of every community, of peace and of justice in the world. (3) The following basic rights shall bind the legislature, the executive and the judiciary as directly applicable law."

50 "Article 1 Human dignity is inviolable. It must be respected and protected."

51 Sobre o tema, v., por todos, Hoffmann-Riem (2016, p. 27- 52). Como contraponto, optando por um modelo dominante de autorregulação, v., entre outros, na literatura brasileira, Hartmann (2018, p. 145-184).
} 
Direitos Humanos na Internet ${ }^{52}$, assim como de um código de ética comum para a Rede, o que poderá vir a ter, quem sabe, resultados mais efetivos e duradouros ${ }^{53}$.

Nessa perspectiva, merece destaque que tramita no Parlamento Europeu projeto (contendo por ora 23 artigos) de uma Carta dos Direitos Fundamentais Digitais da União Europeia, cujo artigo 5º , na versão de 24.04.2018, dispõe ${ }^{54}$ :

Liberdade de Opinião e esfera pública.

1 - Cada ser humano tem o direito de manifestar sua opinião de modo livre no mundo digital;

2 - Tal direito encontra seus limites nas prescrições contidas nas leis gerais;

3 - Promotores de espaços discursivos públicos são responsáveis pela proteção da liberdade de expressão. Eles têm por obrigação assegurar a observância dos direitos fundamentais e deveres consagrados nessa Carta de acordo com o disposto nas leis.

De qualquer sorte, também a efetividade de tais marcos normativos também dependerá da sua receptividade e da indispensável auto vinculação por parte dos Estados e de todos os atores da Internet, o que somente será viável - e mesmo assim como limites - mediante uma rede de cooperação e interação política e jurídica multinível e num esquema de - aqui reforçamos o nosso pensamento - de uma modalidade de autorregulação regulada.

\section{REFERÊNCIAS}

BARROSO, Luís Roberto. Liberdade de expressão versus direitos da personalidade. Colisão de direitos fundamentais e critérios de ponderação. In: BARROSO, Luís Roberto. Temas de Direito Constitucional. v. III, Rio de Janeiro: Renovar, 2005.

BETHGE, Herberth. Meinungsfreiheit, Art. 5. In: SACHS, Michael (Hsgb). Grundgesetz Kommentar, 8. ed. München: C.H. Beck, 2018.

BRASIL. Supremo Tribunal Federal. ADI 4.451/DF, Relator Ministro Alexandre de Moraes, j. 21.06.2018 (2018).

\footnotetext{
52 Nesse sentido, v. a United Nations (2018) Charter of Human Rights and Principles for the Internet.

${ }^{53} \mathrm{O}$ tema da ética na Internet não é novo e já existe farta literatura a respeito, como, por exemplo, Koenig e Rustad (2017). Da mesma forma já são muitos os códigos ou regulamentos editados por usuários e demais atores da Rede, incluindo as mídias sociais e provedores de pesquisa.

54 V. https://digitalcharta.eu/.
} 
BRASIL. Supremo Tribunal Federal. ADI 4815, relạ. Minª Cármen Lúcia. Tribunal Pleno, j. 10.06.2015 (2015).

BRASIL. Supremo Tribunal Federal. ADPF 130, rel. Min. Carlos Britto. Tribunal Pleno, j. 30.04.2009 (2009).

BRASIL. Supremo Tribunal Federal. ADPF 187, rel. Min. Celso de Mello. Tribunal Pleno, j. 15.06.2011 (2011).

BRASIL. Supremo Tribunal Federal. Habeas Corpus (HC) 84292/RS, rel. Min. Moreira Alves, relator p/ acórdão Min. Maurício Corrêa. Tribunal Pleno, j. 17.09.2003 (2003).

BRUGGER, Winfried. Sollte Hassrede verboten oder geschützt werden? Ein Konflikt zwischen Deutschland und Amerika. In: MEIER, Horst [Herausgeber]. Rechtsradikale unter dem Schutz der Versammlungsfreiheit. Evangelische Akademie Hofgeismar, 2010.

BRUGGER, Winfried. Verbot oder Schutz von Hassrede? AÖR 128, 2003.

DEUTSCHLAND. Bundesverfassungsgericht. 1 BvR 673/18 - Rn. (1-37), 2018. Disponível em: http://www.bverfg.de/e/rk20180622_1bvr067318.html. Acesso em: 24 out. 2018.

DEUTSCHLAND. Gesetz zur Verbesserung der Rechtsdurchsetzung in sozialen Netzwerken (Netzwerkdurchsetzungsgesetz - NetzDG), de 1. September 2017 (BGBl. I S. 3352), 2017. Disponível em: <https://www.gesetze-iminternet.de/netzdg/NetzDG.pdf>. Acesso em: 24 out. 2018.

EUROPEAN UNION. CEDH, Cour (Deuxième Section), 27 juin 2017, n. 34367/14, 2017. Disponível em: <www.doctrine.fr/d/CEDH/HFDEC/ADMISSIBILITY/2017/ CEDH001-175941. Acesso em: 1 out. 2018.

EUROPEAN UNION. Council of Europe. European Council Recommendation n. 97/20 of the Committee of Ministers to member states on "hate speech", 1997.

EUROPEAN UNION. Directive 2000/31/EC of the European Parliament and of the Council of 8 June 2000 on certain legal aspects of information society services, in particular electronic commerce, in the Internal Market ('Directive on electronic 
commerce'), 2000. Official Journal L 178, 17/07/2000 P. 0001 - 0016. Disponível em: $<$ https://eur-lex.europa.eu/legal-content/EN/TXT/HTML/ ?uri=CELEX:32000L0031 \&from=pt>. Acesso em: 30 out. 2018.

EUROPEAN UNION. European Commission. Code of Conduct on Countering Illegal Hate Speech Online, 2018. Disponível em: <<https://ec.europa.eu/info/ sites/info/files/code_of_conduct_on_countering_illegal_hate_speech_online_en.pd f>. Acesso em: 24 out. 2018.

GERSDORF, Hubertus. Hate Speech in sozialen Netzwerken. MMR 2017.

HARTMANN, Ivar Alberto. Liberdade de expressão e capacidade comunicativa: um novo critério para resolver conflitos entre direitos fundamentais informacionais. Revista Direitos Fundamentais \& Justiça, v. 12, 2018, p. 145-184.

HOFFMANN-RIEM, Wolfgang. Selbstregelung, Selbstregulierung und regulierte Selbstregulierung im digitalen Kontext. In: FEHLING, Michael; SCHLIESKY, Utz (Ed.). Neue Macht- und Verantwortungsstrukturen in der digitalen Welt. Baden-Baden: Nomos, 2016.

HOLZNAGEL, Bernd. Das Compliance-System des Entwurfs des

Netzwerkdurchsetzungsgesetzes. ZUM, 2017.

KINGREEN, Thorsten; POSCHER, Ralf. Grundrechte - Staatsrecht II, 34. ed. Heidelberg: C.F. Müller, 2018.

KOENIG, Thomas; RUSTAD, Michael. Global Information Technologies: Ethics and the Law. 1. ed. Kindle Edition Global, West Academic Publishing, 2017.

LANG, Andrej. Netzwerkdurchsetzungsgesetz und Meinungsfreiheit. AÖR 143, 2018.

MICHELMAN, Frank. Relações entre democracia e liberdade de expressão: discussão de alguns argumentos. In: SARLET, Ingo Wolfgang (org.). Direitos fundamentais, informática e comunicação. Porto Alegre: Livraria do Advogado, 2007.

PORRAS RAMIREZ, José Maria. El discurso del ódio como limite a la libertad de expresión em Europa. Revista Direito Público, v. 14, n. 80, 2018. 
SARLET, Ingo Wolfgang; FERREIRA NETO, Arthur M. O direito ao "esquecimento" na sociedade de informação. Porto Alegre: Livraria do Advogado Editora, 2018.

SARMENTO, Daniel. Art. 5음 IV. In: GOMES CANOTILHO, J.J.; MENDES, Gilmar Ferreira; SARLET, Ingo Wolfgang; STRECK, Lênio Luiz (coord.). Comentários à Constituição do Brasil. 2. ed. São Paulo: Saraiva/Almedina, 2018.

SCHRÖDER, Meinhard. Private, statt administrative Durchsetzung des öffentlichen Rechts. Die Verwaltung, v. 50, 2017.

SPINDLER, Gerald. Legal Expertise Commissioned by BITKOM. Göttingen, 2017. Disponível em: <https://www.bitkom.org/ noindex/Publikationen /2017/Sonstiges/Legal-Expertise-Official-2-0.pdf>. Acesso em: 1 out. 2018.

STRUTH, Anna Katharina. Hassrede und Freiheit der Meinungsäusserung. Der Schutzbereich der Meinungsäusserungsfreiheit in Fällen demokratiefeinddlicher Äusserungen nach der Europäischen Menschenrechtskonvention, dem Grundgesetz und der Charta der Grundrechte der Europäischen Union. Berlin: Springer, 2018.

TAKIMOTO, Elika. Até um dia, Facebook. Jornal GGN, 04 de maio de 2017. Disponível em: https://www.diariodocentrodomundo.com.br/ate-um-diafacebook-por-elika-takimoto. Acesso em: 1 out. 2018.

THWEATT, Elizabeth. Bibliography of hate studies materials, 2001. Disponível em: <guweb2.gonzaga.edu/againsthate/thweatt.pdf>. Acesso em: 02.09.2017.

UNITED NATIONS. Charter of Human Rights and Principles for the Internet, 2018. Disponível em: http://internetrightsandprinciples.org/wpcharter. Acesso em: 1 out. 2018.

WALDRON, Jeremy. The harm in hate speech. Cambridge, Massachusetts, London, England: Harvard University Press, 2012.

ZICK, Timothy. The dynamic free speech clause: free speech and its relation to other constitutional rights. New York: Oxford University Press, 2018. 